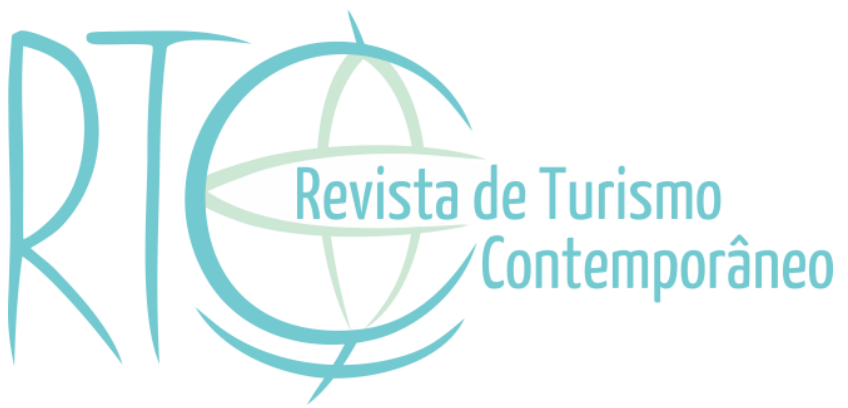

\title{
Política pública como vetor de desenvolvimento do turismo: o caso de Brasília/DF - Brasil
} Public Policy as a development vector of tourism, the case of Brasilia/DF - Brazil

\section{Rayane Ruas}

Mestre em Turismo do Centro de Excelência em Turismo da Universidade de Brasília (UnB), Brasília/DF, Brasil

E-mail: nanyyruas@gmail.com

Artigo recebido em: 21-01-2016

Artigo aprovado em: 29-06-2016 


\section{RESUMO}

Este trabalho tem como tema a política pública e o planejamento como vetor de desenvolvimento do turismo. O objetivo da pesquisa é de investigar de que forma o planejamento turístico conjugado com a política pública interferiu no período entre 2010 e 2014 no desenvolvimento do turismo em Brasília. Para o alcance do objetivo a metodologia utilizada foi de pesquisa bibliográfica e documental. Como instrumentos de trabalho e análise são utilizados os Relatórios de Atividades publicados pela Secretaria de Turismo do Distrito Federal, de 2013 e 2014, além do Relatório de Resultados da Gestão 2011-2014, e do Planejamento Estratégico Institucional de 2011. Ao final da pesquisa conclui-se que o planejamento deve estar sempre alinhado com os interesses públicos e privados e é fundamental para o desenvolvimento do setor de turismo. Quando aliado planejamento e políticas públicas o setor de turismo se desenvolve plenamente.

Palavras-chave: Planejamento, Política Pública, Desenvolvimento do Turismo, Brasília.

\section{ABSTRACT}

This paper themed public policy and planning as tourism development vector. Has aimed to investigate how the tourism planning combined with public policy has interfered during the period from 2010 to 2014 on the development of tourism in Brasilia. To reach the goal, the methodology used was the bibliographical and documentary research. As working tools and analysis are used the Activity Reports published by the Department of Tourism of the Federal District, 2013 and 2014 and the Management Results Report 2011-2014 and the 2011 Corporate Strategic Planning. It was concluded that planning should always be aligned with the public and private interests and is essential to the development of the tourism sector. When combined planning and public policy the tourism develops.

Keywords: Planning, Public Policy, Tourism Development, Brasilia.

\section{INTRODUÇÃO}

A pluralidade cultural brasileira tem sido destaque, além de reconhecida pelos governos e pela sociedade, como uma das principais características do patrimônio do País, ao lado dos recursos naturais, o que pode significar para o turismo a possibilidade de estruturação de novos produtos diferenciados, com o consequente aumento do fluxo de visitantes.

Brasília foi declarada Patrimônio Cultural da Humanidade pela Organização das Nações Unidas para a Educação, a Ciência e a Cultura [UNESCO] - em 1987. Este título representa não só o marco urbanístico-arquitetônico da cidade, expresso pela ousadia de seu modernismo, mas também a bandeira da busca constante pela preservação e melhoria da 
qualidade de vida daqueles que nela vivem ou visitam. Não há no mundo outro bem reconhecido como patrimônio que apresente as proporções desta cidade, o que a torna única.

Conforme apontado por Beni (2007) e por Novo e Silva (2010), a linha mestra do desenvolvimento turístico é o planejamento, e o norteador do planejamento é o conhecimento e a análise crítica da situação atual, que permite a elaboração de diagnóstico e prognóstico para a atividade. Portanto, para que haja uma gestão efetiva da atividade se faz necessário um planejamento bem estruturado e articulado.

Durante os últimos anos de atuação governamental em Brasília observou-se a atividade se desenvolver a partir de um planejamento tímido e o início de uma política pública para o setor. A partir dessa política, Brasília passou a se destacar no cenário nacional e internacional, conforme apontado pelos documentos da Secretaria de Turismo do Distrito Federal. A partir desses dados surge o questionamento de em que medida a inserção de políticas públicas e planejamento para o setor promoveram o seu desenvolvimento ou de fato foram as circunstâncias que levaram a essa evolução.

Esta pesquisa justifica-se na necessidade constante de avaliar, também sob a perspectiva acadêmica, os projetos, planejamentos e até mesmo a política pública no setor de turismo, contribuindo cada vez mais para a sua efetividade. Isto porque se trata de uma área que ainda possui poucos estudos e publicações a respeito (Secchi, 2012).

Justifica-se, também na necessidade de avaliar as publicações governamentais e os resultados apontados por elas, a fim de verificar se as colocações postas coincidem com a realidade vivenciada pelo setor e se houve de fato um incremento no turismo proporcionado pelas políticas. Ainda, esta pesquisa justifica-se pela evidência do tema na atualidade, em um momento que o país vivenciou a Copa do Mundo FIFA 2014 ${ }^{\mathrm{TM}}$, e colheu bons frutos da realização deste megaevento, mas que vive um momento de crise interna e simultaneamente se prepara para a realização de outro megaevento que é as Olimpíadas em 2016.

Por fim, esta pesquisa poderá subsidiar o planejamento e a efetivação da política pública, visando o incremento do turismo e o alcance de melhores resultados econômicos para o país na ocasião das Olimpíadas. Além disso, os resultados desta pesquisa poderão nortear gestores públicos na tomada de decisão.

Portanto, o objetivo geral da pesquisa é investigar como o planejamento turístico conjugado com a política pública interferiu no período entre 2010 e 2014 no desenvolvimento do turismo em Brasília, e tem como objetivos específicos: relacionar o planejamento e as 
políticas públicas do setor de turismo; investigar a efetividade do planejamento e das políticas públicas no turismo; e analisar as interferências que a inserção de planejamento e políticas públicas voltadas para a área provocou no Destino Brasília.

\section{REFERENCIAL TEÓRICO}

O planejamento envolve uma previsão do futuro e tenta diminuir os imprevistos para que o objetivo almejado seja alcançado a partir de ações estabelecidas. Para que haja um bom planejamento se pressupõe uma necessidade de mudança de cenário, sendo o planejamento o meio para se atingir à expectativa (Novo \& Silva, 2010).

No turismo o planejamento é necessário para que destinos se desenvolvam de forma plena, minimizando os impactos negativos da atividade e maximizando os efeitos positivos. Oliveira (2004) aponta que o planejamento turístico deve maximizar os benefícios socioeconômicos e minimizar os custos, visando o bem-estar da comunidade receptora e a rentabilidade dos empreendimentos do setor. Os estímulos da efetiva parceria entre iniciativa pública e privada voltadas à preservação das áreas ambientais da cultura e a manutenção do turismo são cada dia mais comuns.

Segundo Novo e Silva (2010), o planejamento turístico cabe ao poder público, esfera federal, estadual, municipal e no caso de Brasília, Distrital; aos empresários locais, que proporcionam empreendimentos em que a atividade se baseia; às universidades responsáveis pela capacitação no setor, além dos estudos, pesquisas e monitoramento da atividade; à comunidade local, que atua como anfitriã e receptora dos visitantes, além de ser a mão de obra envolvida na atividade; e ainda, às organizações não governamentais.

Ruschmann (2001) destaca os principais objetivos do planejamento turístico do poder público:

a) definir políticas e processos de implementação de equipamentos e atividades e seus respectivos prazos;

b) prover os incentivos necessários para estimular a implantação de equipamentos e serviços turísticos, tanto para empresas públicas como para privadas;

c) maximizar os benefícios socioeconômicos e minimizar os custos (tanto os de investimentos como os de operação), visando ao bem-estar da comunidade receptora e à rentabilidade dos empreendimentos do setor; 
d) minimizar a degradação dos locais e recursos sobre os quais o turismo se estrutura e proteger aqueles que são únicos;

e) capacitar os vários serviços públicos para a atividade turística, a fim de que se organizem e correspondam favoravelmente quando solicitados;

f) garantir a introdução e o cumprimento dos padrões reguladores exigidos da iniciativa privada;

g) garantir que a imagem da destinação se relacione com a proteção ambiental e a qualidade dos serviços prestados (Ruschmann, 2001, p. 69).

Sendo assim, o planejamento turístico se configura como uma ferramenta fundamental para o pleno desenvolvimento da atividade. Entretanto, este planejamento deve envolver todos os seus atores, cabendo ao poder público congregar seus interesses, traçar as diretrizes e, consequentemente, as políticas públicas para o alcance dos resultados almejados. Conforme analisado por Lima (2012) o termo política em português, assim como em outros idiomas latinos, pode assumir duas conotações principais, diferenciados no inglês, que seriam politics e policy. Ao ser utilizado como a primeira conotação do idioma inglês politics tem o sentido de "atividade humana ligada a obtenção de recursos necessários para o exercício do poder sobre o homem" (Secchi, 2012), ou seja, um conjunto de relações formais ou informais que expressam relações de poder. Quando o termo política assume o sentido de policy, possui uma conotação mais concreta voltado às orientações para a decisão e ação. A política consiste em uma relação diplomática, formalizada por termos ou documentos ou, ainda, informalmente, realizada através do diálogo, que tratam as relações de poder, de "troca de favores" em busca de uma resolução pacífica para conflitos de interesses (Rua, 1998).

Quando se refere ao interesse público, esta é chamada de Política Pública. Sendo assim, entende-se que a Política Pública, é todo o procedimento que se destinam a resolução de conflito de interesses que visam o benefício da população como um todo. Entretanto, Secchi (2012) afirma que qualquer definição de política pública é arbitrária, pois não há consenso na literatura especializada sobre questionamentos básicos.

Conceição e Gomes (2015) apontam que as políticas públicas adotadas por determinados governantes demonstram um conjunto de características da realidade social, das prioridades atendidas e o que se tem dado mais atenção no contexto em que a política se insere. Segundo Lima (2012) a política pública é um conjunto de decisões e não uma decisão isolada, onde as demandas e os atores sociais são elementos importantes na constituição das 
políticas públicas. Sendo assim, dentre outras, cabe ao poder público definir políticas que impulsionem a atividade, promover os incentivos necessários para estimular o setor e capacitar os vários serviços públicos para a atividade, visando assim o seu desenvolvimento. Ações estas que devem ser apresentadas à sociedade por meio de políticas públicas.

Faria (2012) analisa que desenvolvimento é um termo ambíguo usado para descrever o movimento de uma sociedade de uma condição para outra. Aponta, ainda, que o desenvolvimento é a satisfação crescente das necessidades básicas de uma população, a redução das desigualdades sociais e expansão da liberdade do indivíduo.

O incentivo ao turismo em geral é justificado pela sua capacidade de desenvolvimento de uma localidade. Barros, Silva, Granero e Braga (2008) apontam que quando bem planejado o turismo pode ser um gerador de empregos e riqueza, uma via de intercâmbio cultural, um caminho para a conservação das belezas naturais e culturais, além de gerador de positivas mudanças sociais.

Tendo em vista que este artigo trata de uma análise de documentos de planejamento e políticas públicas, os conceitos apresentados servem de subsídio para o melhor entendimento das informações apresentadas. $\mathrm{Na}$ análise de dados apresentando o contexto em que foram elaborados o planejamento e a política pública para o destino, e o cenário após 4 anos da sua atuação.

\section{METODOLOGIA}

A metodologia utilizada para alcance dos objetivos é pautada na técnica de pesquisa bibliográfica. Gil (1989, p. 71) aponta que "a pesquisa bibliográfica é desenvolvida a partir de material já elaborado, constituído principalmente de livros e artigos científicos".

Todo o processo de coleta de dados e análise está baseada na pesquisa bibliográfica. Poupart, Deslauriers, Groulx, Laperrière, Mayer, \& Pires (2008) acrescenta que a pesquisa bibliográfica não está limitada à parte inicial, mas sim ao longo do trabalho com um papel fundamental de guiar o pesquisador em função do movimento do objeto. Além da pesquisa bibliográfica foi utilizada a técnica de pesquisa documental. Lakatos e Marconi (2003) apontam que a pesquisa documental se baseia na coleta de dados restrita a documentos, escritos ou não, que se constituem de "fonte primária", ou seja, que ainda não passaram por um tratamento de informações.

Gil (1989, p. 71) aponta que 
Enquanto a pesquisa bibliográfica se utiliza de fundamentalmente das contribuições dos diversos autores sobre determinado assunto, a pesquisa documental vale-se de materiais que não receberam ainda um tratamento analítico. [...] Existem, de um lado, os documentos de primeira mão, que não receberam qualquer tratamento analítico, tais como: documentos oficiais, reportagens de jornais, cartas, contratos, diários, filmes, fotografais, gravações, etc. De outro lado, existem os documentos de segunda mão, que de alguma forma já foram analisados, tais como: relatórios de pesquisa, relatórios de empresas, tabelas estatísticas etc.

Como instrumentos de trabalho e análise são utilizados os Relatórios de Atividades publicados pela Secretaria de Turismo do Distrito Federal, de 2013 e 2014, além do Relatório de Resultados da Gestão 2011-2014, e do Planejamento Estratégico Institucional de 2011.

Para comparar os cenários é utilizado Índice de Competitividade do Turismo Nacional, Destinos Indutores do Desenvolvimento Turístico Regional - Destino Brasília, de 2013 - que possui o historio dos anos anteriores - e 2015 que apresenta o cenário atual. Segundo o Ministério do Turismo (2013), tal índice foi implementado com o objetivo de fornecer um retrato detalhado do setor, possibilitando assim uma intervenção planejada em um grupo de destinos importantes para o desenvolvimento do turismo no país.

A metodologia utilizada para a elaboração do Índice de Competitividade do Turismo Nacional visa permitir a identificação de pontos fortes e fracos de cada um dos destinos divididos em 13 dimensões - Infraestrutura Geral, Serviços e Equipamentos Turísticos, Acesso, Atrativos Turísticos, Marketing e Promoção do Destino, Políticas Públicas, Cooperação Regional, Monitoramento, Economia Local, Capacidade empresarial, Aspectos Sociais, Aspectos Ambientais e Aspectos Culturais. Bem como, avaliá-los em uma escala de 1 a 100 (Ministério do Turismo, 2013).

\section{ANÁLISE E DISCUSSÃO DOS RESULTADOS \\ 4.1 PLANEJAMENTO ESTRATÉGICO INSTITUCIONAL}

Visando a efetivação das políticas públicas a Secretaria de Estado de Turismo [SETUR]-DF, órgão de direção superior diretamente subordinada ao Governador do Distrito Federal, elaborou Planejamento Estratégico Institucional em parceria com a Subsecretaria de Modernização da Gestão da Secretaria de Estado de Planejamento e Orçamento [SEPLAN]. 
O Planejamento Estratégico Institucional (Mapa Estratégico, Plano de Ações e Quadro de Indicadores e Metas) foram validados pela instância de governança do destino - Conselho de Desenvolvimento do Turismo do Distrito Federal [CONDETUR]-DF - em sua $10^{\mathrm{a}}$ Reunião Ordinária, em 2012.

O Mapa Estratégico apresenta os objetivos da instituição, divididos em 4 perspectivas: de governo (valor público gerado ao governo); cliente/beneficiário (quais os segmentos atendidos e quais valores serão agregados a estes segmentos); processos internos (que requisitos devem pautar os processos internos); e aprendizagem e crescimento (que competências organizacionais serão desenvolvidas). Estes objetivos, associados às perspectivas, apresentam um quadro do que seria desenvolvido institucionalmente para que seja cumprida a missão estabelecida.

Figura 1: Mapa Estratégico da Secretaria de Estado de Turismo do Distrito Federal - SETUR/DF 2011 a 2014

\section{Mapa Estratégico da SETUR}

Missão: Desenvolver o turismo no Dis trito Federal a partir do fomento e promoção de produtos e serviços com articulação entre o poder público e setor privado.

Visão: Tornar o Distrito Federal, pela oferta de produtos e serviços, um dos principais destinos turísticos do Brasil.

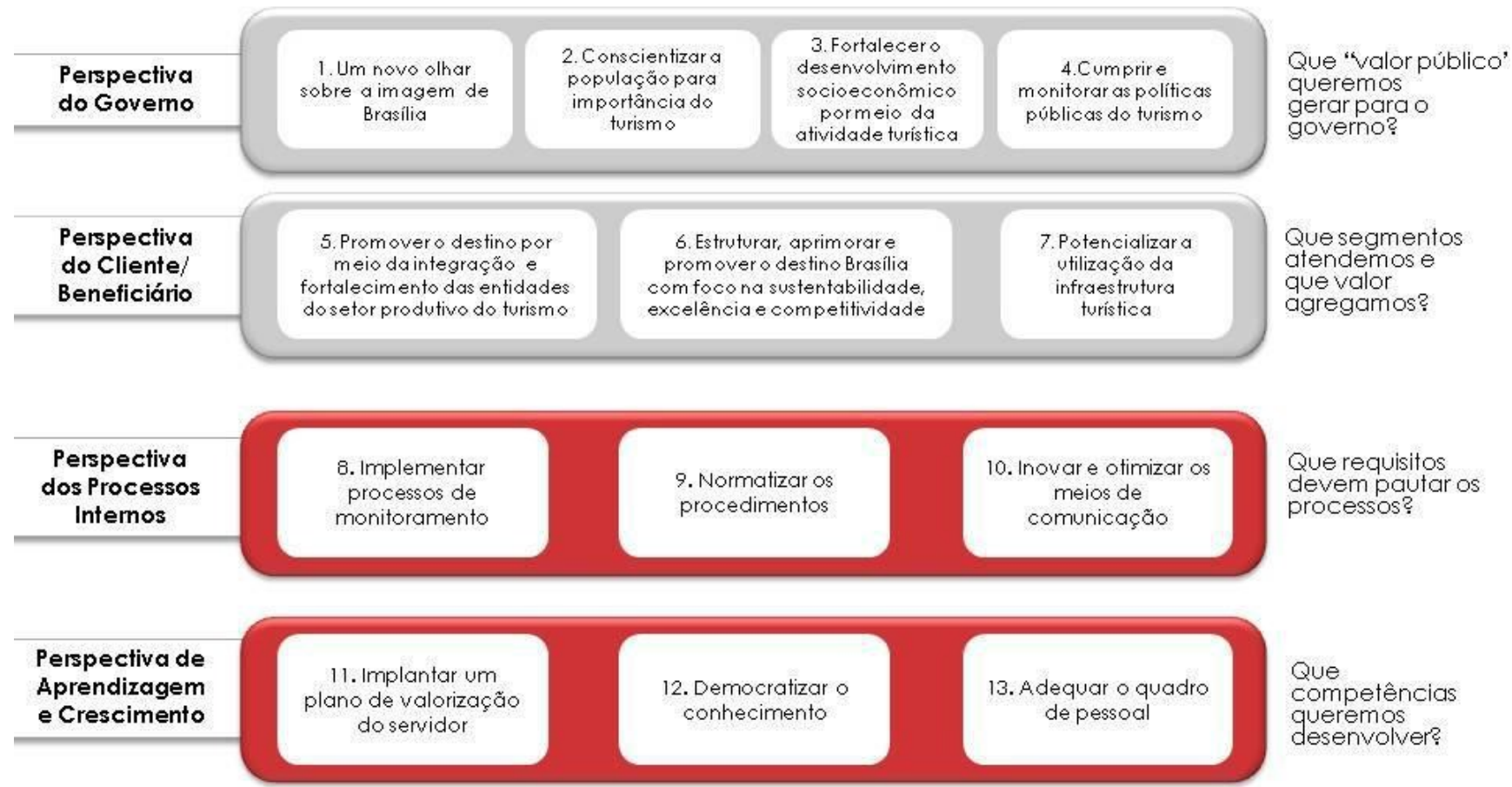

Fonte: Secretaria de Estado de Turismo. (2011). Planejamento Estratégico Institucional. 
Conforme documento da Secretaria de Estado de Turismo (2011), foi elaborado um conjunto de metas com o intuito de mensurar e avaliar o desenvolvimento do planejamento. Com base no acompanhamento das metas, é possível aferir a efetividade das ações para atingir os objetivos. As metas definidas estão listadas a seguir (Secretaria de Estado de Turismo, 2011):

\section{Metas Gerais:}

Aumentar o fluxo em $30 \%$ de turistas nacionais e internacionais; Aumentar de dois para três dias o tempo de permanência do turista no DF;

Aumentar em $20 \%$ das propostas/sugestões e/ou demandas dos conselheiros CONDETUR-DF;

Realizar nove ações por ano de promoção nacional e internacional do destino Brasília-DF;

Qualificar direta ou indiretamente quatro mil profissionais que atuam nas atividades turísticas conexas e/ou correlatas ao Turismo; Aumentar em 30\% eventos geradores de fluxo turístico no destino Brasília;

Aumentar em $25 \%$ o número de eventos captados para o destino Brasília.

Ampliar em 200\% o quadro de servidores efetivos na SETUR/DF; Melhorar a infraestrutura dos equipamentos turísticos (próprios/SETUR) em 50\%;

Adequar a gestão do turismo com indicadores de monitoramento no destino Brasília DF em 100\%.

\subsection{CONTEXTO DO TURISMO 2010}

Identifica-se relevante conhecer o cenário do turismo em 2010, para que seja realizado um comparativo com o cenário de 2014, possibilitando assim uma análise da evolução dos principais fatores.

Segundo informações do Instituto Pesquisa e Estatística Aplicada [IPEA], em 2010 a turismo com as suas Atividades Características do Turismo - ACTs (alojamento, alimentação, transportes, auxiliar de transportes, aluguel de transportes, agências de viagem, cultura e lazer) empregava formalmente 890.326 pessoas em dezembro de 2009 .

O setor de turismo contribuiu com 2,24\% do PIB do Distrito Federal enquanto que o no turismo nacional o setor de turismo correspondeu a 4,39\% do PIB,o que se configura um potencial para desenvolver a atividade turística no DF. 
Quanto à motivação para visita à Brasília em 2008, ano em que se tem pesquisas, o lazer representava 4,89\%, negócios 48,26\%, convenções $16,99 \%$ e outros $29,85 \%$. Ou seja, o segmento de negócios e eventos representava 65,25\% (Secretaria de Turismo, 2013).

Segundo informações da Associação Internacional de Congressos e Convenções [ICCA] (2011), no ano de 2010 foram realizados 12 eventos internacionais e Brasília ocupou o $3^{\circ}$ colocado no ranking nacional e o $149^{\circ}$ colocado no ranking mundial.

A Empresa Brasileira de Infraestrutura Aeroportuária [INFRAERO] (2015) aponta que em se tratando da movimentação aérea, o aeroporto de Brasília já era um importante hub do país com um fluxo aéreo de 14,3 milhões de passageiros ao ano.

Com relação a hospedagem em 2010 foram identificados 52 equipamentos hoteleiros de todos os portes na RA I - Brasília sendo 7.975 UH's e 13.539 leitos (Secretaria de Turismo, 2013).

Ressalta-se, ainda que em documento elaborado pelo Grupo Gestor de Brasília (2009) o destino possuía a imagem de cidade dos políticos corruptos e não se falava em desenvolver o turismo na capital federal. Predominava o costume dos moradores da cidade de viajar e visitar os parentes a cada feriado, mas não era usual convidar os familiares para conhecer Brasília. Para os empresários do setor, o turismo era uma atividade consolidada pelo caráter espontâneo, atrelada aos políticos e empresários que visitavam a cidade semanalmente para tratar de assuntos profissionais. Pelos próprios brasilienses a capital era reconhecida como "o lugar que não tem o que fazer", não se podia falar de uma apropriação do título de cidade patrimônio reconhecido internacionalmente. Diante do aspecto político, Brasília se encontrava fragilizada no âmbito da legislação para o turismo com inúmeras lacunas que dificultavam a operacionalização da atividade, bem como a continuidade das ações de políticas públicas.

\subsection{AVANÇOS ALCANÇADOS NO DESENVOLVIMENTO DO TURISMO}

O desenvolvimento e os avanços das ações alcançadas pela secretaria de turismo, é apresentado dividido em 6 dimensões: Política Pública, Monitoramento, Promoção do Destino, Infraestrutura, Serviços e Equipamentos Turísticos e Captação de Eventos. Em seguida a apresentação da evolução das metas gerais.

Estas dimensões foram selecionadas porque se observou que as ações da Secretaria de Turismo convergiam para elas, e impactavam diretamente no seu desenvolvimento. Ressaltase que estas dimensões estão no Estudo de Competitividade do Ministério do turismo, e por se 
tratar de um estudo amplo, realizado em nível nacional e imparcial, configura-se como um instrumento de verificação do desenvolvimento.

- Política Pública.

A partir da consolidação da política pública e da existência de legislação consistente é que se torna possível um desenvolvimento do turismo em um território.

Portanto, apresentaremos o cenário em 2010 da política pública no DF, e a sua evolução até 2014, finalizando com a comparação do Estudo de Competitividade, que se configuram como indicadores externos e consolidam a análise da evolução de cenário do destino.

Tabela 1: Comparação de Cenário - Políticas Públicas

\begin{tabular}{l|lc}
\multicolumn{1}{c|}{ Cenário 2010} & \multicolumn{1}{c}{ Cenário 2014} \\
\hline $\begin{array}{l}\text { - Ausência de Legislação e Normatização para o } \\
\text { setor }\end{array}$ & $\begin{array}{l}\text {-Fortalecimento desenvolvimento } \\
\text { socioeconômico por meio da atividade turística }\end{array}$ \\
- Pouco reconhecimento do turismo como fator de & - Fomento das políticas públicas de turismo \\
desenvolvimento socioeconômico & - Normatização do setor de Turismo \\
- Falta de projetos estratégicos para formulação de & - Consolidação da instância de governança local \\
políticas públicas de turismo &
\end{tabular}

Fonte: Relatório de Gestão - Secretaria de Turismo (2014)

A partir da Tabela 1 identifica-se uma mudança no cenário, o fortalecimento do desenvolvimento socioeconômico pode ser verificado ao avaliar o quantitativo de mão de obra formal nas Atividades Características do Turismo, em que houve um aumento de 10,66\% alcançando 985.348 pessoas empregadas em 2013, segundo dados do IPEA (2013).

O fomento a políticas públicas e a normatização do setor foram se justificam com a publicação da Política Pública de Turismo, Lei No 4.883, de 11 de Julho de 2012, (Brasil, 2012) e a publicação de 9 decretos e 4 portarias de normatização da atividade turística no Distrito Federal.

E a consolidação da instância de governança local se deu com a continuidade e o fortalecimento do Conselho de Desenvolvimento do Turismo, que foi reativado no final de 2011.

Observa-se, portanto, um avanço na dimensão de Política Pública no Destino Brasília, que pode ser constatado pelo o índice de Competitividade, aferido pelo Ministério do Turismo, com um crescimento de mais de 9 pontos percentuais, com 60,5 em 2010 e 69,4 em 
2014, colocando Brasília mais de 6 pontos a cima da média das capitais Brasileiras (63,9 em 2014).

No entanto, sabe-se que ainda um caminho a ser percorrido na dimensão de Política Pública para fornecer ao destino subsídios legais para que se fortaleça e se desenvolva na plenitude da sua capacidade.

\section{- Monitoramento.}

Independente do âmbito territorial o monitoramento é uma necessidade para mensurar o desempenho. No setor turístico o monitoramento se configura como uma necessidade primordial para o Planejamento e análise da evolução do destino. Apresentado a segui os cenários da temática:

Tabela 2: Comparação de Cenário - Monitoramento

\begin{tabular}{|c|c|}
\hline Cenário 2010 & Cenário 2014 \\
\hline $\begin{array}{l}\text { - Ausência de informações para planejamento e } \\
\text { gestão }\end{array}$ & $\begin{array}{l}\text { - Monitoramento da Atividade Turística no destino } \\
\text { Brasília/DF }\end{array}$ \\
\hline $\begin{array}{l}\text { - Ausência de dados para o monitoramento do } \\
\text { destino Brasília/DF }\end{array}$ & $\begin{array}{l}\text { - Desenvolvimento do destino com foco na } \\
\text { sustentabilidade e na competitividade }\end{array}$ \\
\hline
\end{tabular}

Fonte: Relatório de Gestão - Secretaria de Turismo, (2014)

A implementação do Observatório do Turismo (http://observatorio.setur.df.gov.br) no destino provocou uma mudança completa no cenário do monitoramento, do planejamento e da gestão da atividade.

O Observatório consiste em uma importante ferramenta de monitoramento do destino, com o acompanhamento periódico dos indicadores mais importantes das atividades turísticas, tais como perfil do visitante e preferências de viagem, movimentação terrestre e aeroportuária, ocupação hoteleira, número de visitação aos principais atrativos, dentre outras.

Com a maior parte dos indicadores sendo atualizados mensalmente, o Observatório realiza, estudos macro e microeconômico, análises setoriais, e ainda específicas de nichos e tendências de mercado.

Diante deste panorama, entende-se que saiu de um patamar de ausência sistemática e ordenada de dados para o a condição de informações coletadas e atualizadas mensalmente que contribuem para o Monitoramento do Turismo no DF. Inclusive, o Ministério do Turismo buscou a metodologia implementada em Brasília como referência para os observatórios do turismo no país.

No Estudo de Competitividade de 2014 o monitoramento da atividade turística deu um salto, saindo de 56,6 em 2010, 54,5 em 2013 e 71,4 em 2014. Atestando a complexidade e a relevância de ferramenta do Observatório para o monitoramento. 
Como já apontado, o monitoramento do destino é essencial para o seu desenvolvimento, portanto para o avanço de Brasília enquanto Capital Federal ressalta-se a necessidade da continuidade da ferramenta de monitoramento, bem como a sua alimentação periódica para que a série histórica seja mantida e se tenha condições de realizar comparativos, identificar oportunidades e lacunas.

\section{Promoção do Destino.}

A promoção do destino se revela como fundamental no desenvolvimento da atividade turística. O maior legado da Copa do Mundo FIFA 2014 ${ }^{\mathrm{TM}}$ foi a ampla promoção das cidadessede, na qual Brasília se destacou como destino turístico, posicionando-se como capital d país e cidade patrimônio para brasileiros e estrangeiros.

A evolução da promoção se evidencia na análise do Cenário 2010 e 2014, bem como no Índice de Competitividade aferido pelo Ministério do Turismo:

Tabela 3: Comparação de Cenário - Promoção do Destino

\begin{tabular}{l|l}
\multicolumn{1}{c|}{ Cenário 2010} & \multicolumn{1}{c}{ Cenário 2014 } \\
\hline - Imagem de Brasília associada à política & - Novo olhar para a imagem da cidade enquanto \\
- Inexpressiva divulgação turística no mercado & $\begin{array}{l}\text { cidade da diversidade cultural e gastronômica } \\
\text { - Promoção da cidade em feiras e eventos nacionais e } \\
\text { internacionais }\end{array}$ \\
nacional e internacional & $\begin{array}{l}\text { - Atendimento ao turista priorizado e reconhecido } \\
\text { - Precário atendimento ao turista }\end{array}$ \\
- Inexpressível reflexo de hospitalidade & - Mudança no conceito de hospitalidade
\end{tabular}

Fonte: Relatório de Gestão - Secretaria de Turismo (2014)

O novo olhar sobre a imagem da cidade voltado para a diversidade cultural e gastronômica e a mudança no conceito de hospitalidade atingiu o seu ponto alto durante a realização o mundial, onde Brasília alcançou $96 \%$ de satisfação do turista quanto à hospitalidade, segundo pesquisas do Ministério do Turismo, ficando em primeiro lugar.

Visando posicionar a Capital como cidade sede da Copa do Mundo, e como Capital do país, foi intensificada a participação em feiras e eventos, com mais de 50 participações em 2013 (Secretaria de turismo, 2014).

Com relação ao atendimento ao turista no Relatório de Atividades de 2014 a Secretaria de Turismo aponta que o planejamento e a política pública priorizaram a abertura de Centros de Atendimento a Turista, no decorrer dos 4 anos foram 7 fixos e 2 móveis (vans, que podem estacionar próximo a eventos e locais de grande fluxo de visitantes), todos com atendentes capacitados e bilíngues. $\mathrm{Na}$ ocasião da Copa do Mundo estes postos foram reforçados por outros 13 pontos de atendimento, inclusive dentro do estádio e no Fifa Fan Fest. 
Toda a mídia espontânea alcançada durante a realização da Copa do Mundo, somada às inúmeras ações de promoção pré evento, de preparação e organização da cidade para realizar com excelência um megaevento e de hospitalidade concederam a Brasília um reposicionamento de imagem iniciando uma nova era para o turismo na Capital Federal.

O índice de competitividade apontou um aumento de 36 pontos, saindo de $26,8 \mathrm{em}$ 2010 para 69,4 em 2014. Entretanto, sabe-se que marketing deve possuir um conjunto de ações continuadas para que trabalho desenvolvido não se perca.

\section{- Infraestrutura Turística}

A infraestrutura é imprescindível para o desenvolvimento da atividade turística no destino. Antes de se desenvolver um destino turístico ele deve oferecer infraestrutura condizente com o a sua oferta, que atenda o morador e proporcione uma boa estada ao visitante.

Ao comparar o cenário 2010 com o de 2014, identifica-se um avanço na dimensão de infraestrutura turística.

Tabela 4: Comparação de Cenário - Infraestrutura Turística

\begin{tabular}{|c|c|}
\hline Cenário 2010 & Cenário 2014 \\
\hline $\begin{array}{l}\text { - Sinalização da cidade inalterada desde a década de } \\
70 \\
\text { - Pouca priorização para restauração, modernização e } \\
\text { melhorias da infraestrutura turística no destino } \\
\text { Brasília/DF } \\
\text { - Ausência de novos investimentos de infraestrutura } \\
\text { turística }\end{array}$ & $\begin{array}{l}\text { - Melhor estruturação do Destino } \\
\text { - Instalação de sinalização viária e turística } \\
\text { - Potencialização da utilização da infraestrutura } \\
\text { turística }\end{array}$ \\
\hline
\end{tabular}

Fonte: Relatório de Gestão - Secretaria de Turismo, (2014)

Conforme relatos de documentos citados anteriormente, em 2010 a atividade turística não era incentivada pelo governo, no entanto em 2014 identifica-se um avanço na estruturação de atrativos turísticos da cidade, onde se destaca a revitalização do complexo da Torre de TV, com a restauração da fonte luminosa, substituição dos elevadores que levam ao mirante, revitalização da feira de artesanato, e a implantação de calçadas e do projeto de paisagismo. Após a reinauguração a Torre de TV foi incorporada à vida do morador da cidade, sendo cada vez mais visitada e utilizada com espaço de lazer (Secretaria de Turismo, 2014).

Foi implementada, ainda, a sinalização turística viária, com a implementação de mais de 100 placas de sinalização da cidade, dentro dos padrões internacionais. Segundo o Relatório de Atividades 2014, os atrativos turísticos não só foram identificados, como contaram com uma placa descritiva do monumento em português, inglês e espanhol. 
Ao observar as variáveis e ações desenvolvidas pela Secretaria de Turismo, observa-se que elas não integram a dimensão de infraestrutura do Índice de Competitividade, mas estão difundidas em várias dimensões com ênfase em Serviços e Equipamentos que será apresentada a seguir.

\section{- Serviços e Equipamentos Turísticos.}

A dimensão de Serviços e Equipamentos Turísticos envolve toda a infraestrutura voltada para o atendimento das necessidades dos turistas, tais como atendimento ao turista, qualificação, sinalização e capacidade de atendimento dos equipamentos Turísticos.

A evolução desta dimensão pode ser observada na comparação do cenário 2010 e 2014 desta dimensão e da infraestrutura, bem como na análise do Índice de Competitividade.

Tabela 5: Comparação de Cenário - Serviços e Equipamentos Turísticos

Cenário 2010

- Pouca disponibilidade de serviços que fortaleçam a imagem da cidade para o morador enquanto cidade turística

- Pouca visibilidade da produção associada ao turismo

- Necessidade de qualificação no setor turístico

Fonte: Relatório de Gestão - Secretaria de Turismo, ( 2014)

Segundo Relatório de Gestão 2011-2014, foram capacitadas no âmbito do turismo, mais de 2.000 profissionais. Sabe-se que as demandas de qualificação vã além desse quantitativo, mas a sua realização foi considerada como um avanço.

Visando maior contato entre os artesãos e trabalhadores manuais dos visitantes, foram ampliados os espaços de comercialização da produção associada ao turismo em feiras e eventos ocorridos na cidade.

Com a valorização dos equipamentos turísticos e a sua estruturação promovida pela infraestrutura, somadas às ações de qualificação, fomento à Produção Associada ao Turismo e apropriação do morador, Brasília alcançou uma nova condição de cidade turística.

O índice de competitividade consolida estes resultados, onde Brasília obteve um crescimento de quase 11 pontos percentuais, de 60,5 em 2010 e alcançando índice 71,7 em 2014.

Os Serviços e Equipamentos turísticos merecem atenção constante para que não haja degradação e depreciação do seu valor. Ainda, sempre há possibilidade de inovação e de incremento de atrativos e serviços turísticos que podem fortalecer ainda mais um destino enquanto cidade turística. 


\section{- Captação de Eventos.}

A captação de grandes eventos para um destino se configura como um propulsor da economia local gerando desenvolvimento socioeconômico para a cidade.

Tabela 6- Comparação Cenário -Captação de Eventos

\begin{tabular}{|c|c|}
\hline & Cenár \\
\hline $\begin{array}{l}\text { - Tímida captação de eventos para o destino } \\
\text { Brasília/DF } \\
\text { - Pouco envolvimento do mercado na captação de } \\
\text { eventos }\end{array}$ & $\begin{array}{l}\text { - Captação de eventos efetiva } \\
\text { - Aproximação do setor de turismo nas ações de } \\
\text { captação } \\
\text { - Priorização da captação de eventos na estratégia de } \\
\text { governo }\end{array}$ \\
\hline
\end{tabular}

Fonte: Relatório de Gestão - Secretaria de Turismo ( 2014)

A captação de eventos teve a sua primeira conquista ou ser priorizada pelo governo e inserida em seu planejamento. A partir de então, os esforços foram profissionalizados e a captação de eventos para destino passou a ser ativa, contando com a participação e contribuição do setor privado que trouxe resultados muito positivos para a cidade.

Dentre os principais eventos captados para Brasília, destacam-se a Gymnasíade, Universíade, Fórum Mundial das Águas, além de Congressos Nacionais e Internacionais.

Ao observar a evolução do cenário da captação de eventos identifica-se avanços na sua estruturação, o que resulta na maior efetividade da captação de eventos e maiores benefícios para o destino.

Ressalta-se que a captação de eventos não é aferida pelo Índice de competitividade, mas sim a realização de eventos enquanto atrativos turísticos. Como a maior parte dos eventos são captados com um longo espaço de tempo para sua execução ( 2 ou mais anos), os reflexos desta captação ainda não influenciaram o índice.

\section{- Metas Gerais}

A partir das ações e resultados apresentados, identifica-se o alcance das metas gerais propostas no PPA 2012-2015, tendo como marco inicial de referência o ano de 2011. Seguem os resultados das metas:

1 - Aumentar o fluxo de turistas nacionais e internacionais em 30\%: Aumento de $8,5 \%$ no fluxo de passageiros no Aeroporto Internacional Juscelino Kubitschek, aumento de $67,9 \%$ no número de desembarques de turistas estrangeiros.

\section{2 - Realizar, por ano, nove ações de promoção nacional e internacional do destino}

Brasília: Ações de promoção: participação em feiras nacionais e internacionais, famtours, press trips, campanhas de divulgação e material promocional, Aumento de mais de 190\% na realização de ações promocionais do destino Brasília, com uma média de 45 ações por ano. 
3- Aumentar de dois para três dias o tempo de permanência do turista no DF: em 2013 63,2\% dos turistas permaneceram 3 ou mais dias na cidade, durante a Copa do Mundo FIFA 2014, a média de permanência foi de 4,2 dias.

4 - Aumentar em $20 \%$ as propostas, sugestões e/ou demandas dos conselheiros CONDETUR-DF: incremento de 8 propostas em 2011 para uma média de 65 propostas por ano.

5 - Qualificar, direta ou indiretamente, 4000 profissionais que atuam em atividades turísticas conexas ou correlatas ao setor: Durante o período analisado foram qualificadas 2.149 profissionais, e houve um número expressivo de profissionais matriculados em cursos que estão em andamento, $53,7 \%$ da meta foi atingida.

6 - Aumentar em 30\% eventos geradores de fluxo turístico no destino Brasília: Aumento nos últimos 3 anos, de 190\% na realização de eventos geradores de fluxo turístico nos próprios da Secretaria.

7 - Aumentar em 25\% o número de eventos captados para o destino Brasília: no período de 2012 a 2014 foram captados 25 eventos para o destino, o que representa um aumento de $1.150 \%$ no número de eventos captados para o destino.

8 - Melhorar a infraestrutura dos equipamentos turísticos (próprios/SETUR) em $\mathbf{5 0 \%}$ : foi realizada reforma em 2 equipamentos, implementação da sinalização turística, instalação dos letreiros gigantes "Eu Amo Brasília" e reforma nos centros de atendimento ao turista.

9: Adequar em $100 \%$ a gestão do turismo com indicadores de monitoramento no destino Brasília: em 2013 foi implementado o Observatório de Turismo do Distrito Federal, ferramenta que proporciona o monitoramento da atividade.

10 - Meta: Ampliar em 200\% o quadro de servidores efetivos na SETUR/DF: no período o aumento foi de $125 \%$ no número de servidores efetivos na gestão.

O alcance das metas estabelecidas para o PPA 2012-2015 - considerando o cenário de 2013 e 2014 - foi de 80\%. A captação de eventos foi um destaque, com aumento superior ao esperado. 


\section{CONCLUSÕES}

Tendo em vista as características únicas de Brasília, a sua potencialidade para o turismo, o fator alavancador que esta atividade tem para o desenvolvimento socioeconômico de uma cidade ou país, e a relevância do planejamento para que os melhores resultados sejam alcançados, este trabalho teve como tema a política pública e o planejamento como vetor de desenvolvimento do turismo.

Dentro desta temática o problema de pesquisa foi "a realização de um planejamento e a efetividade de políticas públicas voltadas ao setor de turismo impulsiona o desenvolvimento da atividade em um destino turístico?"

Para desvelar o problema de pesquisa proposto foi apresentada um referencial teórico do tema - política pública, planejamento e desenvolvimento turístico - em seguida foi apresentado uma contextualização do turismo em 2010, apontando as principais informações, tanto econômicas como sociais a respeito do turismo, as demandas do setor privado, os planejamentos desenvolvidos e as perspectivas de crescimento.

Ainda na análise foi pontuada a mudança de cenários na perspectiva de 6 dimensões (política pública, monitoramento, promoção do destino, infraestrutura, serviços e equipamentos turísticos e captação de eventos) e a evolução das metas gerais de 2011 até 2014, conforme avaliada pelo documento Relatório de Gestão da Secretaria de Turismo.

Diante da análise dos dados coletados conclui-se que o planejamento conjugado com a política pública foi fundamental para o desenvolvimento do turismo no período estudado. $\mathrm{O}$ Índice de Competitividade constata este desenvolvimento, apenas no índice geral em 2010 Brasília possuía 69,6 e em 2014 alcançou 75,2, 7 pontos superior à média das capitais brasileiras.

Ao avaliar as ações executadas e as metas traçadas, identifica-se que a atuação do órgão de turismo balizou suas ações e direcionou os seus esforços coordenados com o planejamento e visando alcance da meta. Em alguns casos, observou-se que as metas foram subdimensionadas, entretanto por se tratar de um primeiro planejamento de turismo, tais equívocos não prejudicaram as ações e o desenvolvimento do destino.

Ressalta-se, ainda, a importância da continuidade, tanto do planejamento para o desenvolvimento do turismo no destino, como da implementação das políticas públicas para setor. Entretanto cada vez mais se evidência a importância de um planejamento consistente, não só com os interesses governamentais, mas também que envolva os interesses de empresários do setor e da sociedade civil, alinhados com a política pública. 
Por fim, identifica-se que o objetivo geral da pesquisa, que consistia em "investigar como o planejamento turístico conjugado com a política pública interferiu no período entre 2010 e 2014 no desenvolvimento do turismo em Brasília” foi alcançado. Ressalta-se que a metodologia baseada na técnica de pesquisa bibliográfica e documental foram fundamentais para o desenvolvimento da pesquisa, pois os resultados colhidos foram de documentos internos da secretaria, relatórios de atividades e de gestão, as quais são de livre acesso à população.

Dentre as limitações deste trabalho de pesquisa identifica-se que foi analisado somente a perspectiva interna de gestão do turismo, sem avaliar as impressões dos moradores ou empresários da cidade. Outra limitação foi a análise somente de um estado da federação, sem investigar os demais estados onde o resultado pode ser diferente do encontrado para o Distrito Federal.

\section{REFERÊNCIAS}

Barros, M.O, Silva, S.C, Granero, A.E. \& Braga, H., Filho. (2008). O desenvolvimento do turismo: Uma visão sistêmica. Anais do Congresso Brasileiro de Sistemas. Uni-CACEF, Franca,SP, Brasil, 4

Beni, M.C. (2007). Análise Estrutural do Turismo.(12a Ed.) São Paulo: Senac.

Brasil .(2012). Lei $n^{\circ} 4.883$, de 11 de julho de 2012 - Dispõe sobre a política de turismo do Distrito Federal.

Brasil, Ministério do Turismo.(2013). Índice de competitividade do Turismo Nacional, Destinos Indutores do Desenvolvimento Turístico Regional - Destino Brasília. Brasília: MTur.

Brasil, Ministério do Turismo. (2015). Índice de competitividade do Turismo Nacional Destino Brasília. Brasília: MTur.

Brasil. (2015). Brasília, Patrimônio Cultural da Humanidade.

Conceição, G.C. \& Gomes, M.G.C. (2015). Política Pública, avaliação de políticas públicas e avaliação em profundidade: desvendando conceitos e suscitando discussões rumo a compreensão da temática. Anais do I Encuentro Latino americano de Professores de Política Educativa, II Seminário Internaciconal de Questões de Pesquisa em Educação. UNIFESP. Guarulhos, São Paulo, Brasil, 1, 2.

Dencker, A.F.M. (2007). Pesquisa em Turismo: Planejamento, Métodos e Técnicas. (9a Ed.). São Paulo:Futura. 
Empresa Brasileira de Infraestrutura Aeroportuária. (2015).Estatísticas. Infraero.

Faria, D.M.C.P.(2012). Desenvolvimento e turismo: uma abordagem conceitual. - Belo Horizonte: UFMG/CEDEPLAR.

Gastal, S. (2005). Turismo, imagens e imaginários. São Paulo: Aleph.

Gerhardt, T. E. \& Silveira, D. T. (2009). Métodos de Pesquisa. Porto Alegre: Editora da UFRGS.

Gil, A.C. (1989). Métodos e Técnicas de Pesquisa Social. (2a Ed.) São Paulo: Editora Atlas S.A.

Grupo Gestor de Brasília. (2009). Planejamento do Destino Brasília.

International Congress and Convention Association.(2011). Statistics Report 2010. ICCA

Instituto Pesquisa e Estatística Aplicada.(2013). Sistema de informações sobre o mercado de trabalho no setor turismo-SIMT. IPEA

Lakatos, E.M. \& Marconi, M.A. (2003). Fundamentos de Metodologia Cientifica. (5a Ed.) São Paulo: Editora Altas.

Lima, W.G. (2012). Interface, Política Pública: discussão de conceitos. (5a Ed.).

Novo, C.B.M.C. \& Silva, G.T. (2010). Planejamento e organização do turismo. Amazonas: Centro de Educação Tecnológica do Amazonas. .

Oliveira, D.B. (2004). Revista Turismo. Importância do Planejamento. Revista Turismo

Panosso Netto, A. \& Gaeta, C. (2010). Turismo de Experiência. São Paulo: Senac.

Pires, M. S. (2009). Turismo e a Pós-Modernidade: Teoria, Cultura e Sustentabilidade. Tese de Doutorado. Universidade de Brasília, Brasília, DF, Brasil.

Poupart, J., Deslauriers, J., Groulx, L.H., Laperrière, A., Mayer, R. \& Pires. A.P. (2008). A pesquisa qualitativa: Enfoques epistemológicos e metodológicos. Petrópolis, RJ: Vozes.

Rua, M. G. (1998). Análise de Políticas Públicas: Conceitos Básicos.

Ruas, R. \& Duarte, D.C. (2013). Festivais de Música: um estudo sob a ótica do turismo. Dissertação de Mestrado. Centro de Excelência em Turismo-UnB. Brasília, DF, Brasil.

Rodrigues, L. C. (2013). Avaliação de políticas e programas sociais: princípios teóricometodológicos para uma avaliação em profundidades. In: A. M. Florencio, E. Diogenes \& M.S. Cavalcanti.(Orgs.). Políticas públicas e Estado capitalista: diferentes olhares e discursos circulantes. Maceió: EDUFAL.

Ruschmann, D. (2001). Turismo e Planejamento Sustentável. São Paulo: Papirus. 
Secchi, L.(2012). Políticas Públicas: Conceitos, Esquemas de Análise, Casos Prático. São Paulo: Cengage Learning.

Secretaria de Estado de Turismo-DF. (2011). Planejamento Estratégico Institucional. Brasília: SETUR-DF.

Secretaria de Estado de Turismo-DF. (2013). Relatório de atividades 2013. Brasília: SETURDF.

Secretaria de Estado de Turismo-DF. (2014). Relatório de atividades 2014. Brasília: SETURDF.

Secretaria de Estado de Turismo-DF. (2014). Relatório de Resultados da Gestão 2011-2014. Brasília: SETUR-DF. 